\title{
Design-for-Manufacture Techniques in the Vietnamese Construction Industry: Opportunities and Barriers
}

\author{
Viet Tai Nguyen $^{1}$ and Kriengsak Panuwatwanich ${ }^{2}$
}

\begin{abstract}
The Vietnamese construction industry is currently facing many difficult challenges, notably the dramatic increase in demand for housing, poor working conditions with a high accident rate on site and various environmental issues. To solve these issues, applying better construction techniques is one of the most promising solutions. The design-for-manufacture techniques are popular in many developed countries as they save time, are environmentally friendly, and lead to better quality work, more effective management, and safer working conditions. The research presented in this paper was carried out to determine the feasibility of applying the design-for-manufacture techniques, and evaluate the critical barriers related to adopting these methods. To achieve these goals, comparative analysis and Analytic Hierarchy Process were carried out using data gathered from the Vietnamese construction industry. Additionally, a qualitative study was conducted, with the aim to gain practical and insightful knowledge from Vietnamese construction professionals. According to the result using comparative case study to serve as illustration, design-for-manufacture techniques were found to: reduce the construction time by $42.5 \%$ (save 170 days); reduce the labor and equipment cost by $20 \%$ and $35 \%$ respectively; and provide better working condition and management effectiveness. The qualitative study demonstrates that approximately $80 \%$ of the key figures in the Vietnamese construction industry are convinced that the design-formanufacture techniques could be popular in Vietnam. However, some critical barriers affecting the selection of these techniques were identified, including cost, lack of knowledge, conservatism/negativism, lack of evaluation tools and lack of available suppliers. These barriers were analysed based on specific groups of experts using the Analytic Hierarchy Process technique. The results indicate that negativism, lack of suppliers and lack evaluation of tools were the most important barriers for government officers, constructors and designers, respectively.
\end{abstract}

Keywords: barrier, construction, design, manufacture, Vietnam

\section{Introduction}

The sharp increase in housing demand is one of the most serious problems that many developing countries have to face, and Vietnam is not an exception. A huge population that is quickly expanding and a great deal of migration from rural areas to cities are the main reasons for this issue. The Vietnamese population reached 90 million in 2013 (Michigan State University [MSU], 2014). As a result, the Vietnamese construction industry is faced with a high demand for housing, especially inexpensive housing.

Moreover, many articles have identified high rate of construction accidences on site as another important issues in construction industry. In respect to Vietnam, the Ministry of Labour Invalids and Social Affairs (MOLISA) indicated that there were 5,961 accidents

\footnotetext{
1 Research Student, Griffith School of Engineering, Griffith University, Queensland, Australia, Tel: +614 5996 3593, E-mail: viettai.nguyen@griffithuni.edu.au

2 Senior Lecturer, Griffith School of Engineering, Griffith University, Queensland, Australia, Tel: +617 5552 7357, E-mail: k.panuwatwanich@griffith.edu.au
} 
(involving 6,337 people), which led to 621 fatalities and 2,553 serious injuries, within the Vietnamese construction industry (Tutesigensi \& Phung, 2011).

The Vietnamese construction industry is considered to be a significantly polluted industry due to the use of traditional construction techniques which are not considered to be environmental friendly, these techniques include problems such as the contribution towards air pollution on construction sites, wasting of material: sand, concrete and steel, during the construction process. There are currently three main difficulties in the Vietnamese construction industry. These include a high demand in housing product, a high rate of construction accidents onsite and environmental problems. The design for manufacturing techniques, which is also known as off-site construction, pre-fabricated construction, or manufactured construction techniques, are popular in many developed countries because of the benefits in terms of time, safety, quality, cost, and management effectiveness.

The primary aim of this study is to evaluate the feasibility of the design for manufacturing techniques and to identify the factors that affect the selection these techniques in the Vietnamese construction industry.

\section{Theoretical Background}

\section{Overview}

The advantages, both real and potential, of off-site construction have been widely reported (Goodier \& Gibb 2007; Pan, Gibb \& Dainty, 2007). Therefore, governments worldwide have encouraged the use of design-for-manufacture techniques for many years. Research by Goulding, Pour-rahimian, Arif, \& Sharp (2012) highlighted Japan as the world's most extensive practitioner of manufactured construction. Likewise, the Australian construction industry has identified manufactured construction as important to the improvement of the industry over the next decade (Hampson \& Brandon, 2004). Off-site construction is defined as the manufacture and pre-assembly of building components, elements, or modules before they are installed in their final locations (Goodier \& Gibb, 2007). In this report, design-formanufacture techniques are considered equal to terminologies of the off-site approach, such as off-site production/fabrication, pre-assembly, pre-fabrication, system building, nontraditional building, and industrialized building (Pan, 2006).

\section{Design-for-Manufacture Techniques in Vietnam}

There are mainly two design-for-manufacture techniques used in the Vietnamese construction industry: BubleDeck technique and 3D-Panel wall technique. Thus, these techniques are used as example of design-for-manufacture techniques. The BubbleDeck slab is a biaxial concrete floor system invented and developed by Jorgen Breuning in Denmark in the 1990s (BubbleDeck-UK, 2008). This is a method that involves essentially eliminating all of the concrete that is not performing any structural function from the middle of a floor slab, and by doing so, dramatically reducing structural dead weight (Teja, Kumar, Anusha, Mounika \& Saha, 2012). There are many advantages of BubbleDeck slabs in comparison to traditional slabs. The first and most obvious is that BubbleDeck slabs allows for spans as much as $50 \%$ longer, and need less support than traditional ones (Hai, Hung, Thi, NguyenKhoi \& Phuoc, 2013). Another advantage is that using BubbleDeck slabs reduces the amount of material needed, therefore reducing the construction cost (Prabhu Teja et al., 2012). Last but least, the BubbleDeck slab system is considered both an effective and environmentally friendly form of technology.

The 3D-panel wall is a construction system that was developed based on sandwich panels, and is commonly used worldwide for intensive building production (Gara, Ragni, Roia \& 
Dezi, 2012). These structures are basically created by two concrete layers that are separated by an internal insulation layer of polystyrene. The wall panel receives its strength and rigidity from the diagonal cross wires welded to the welded wire fabric on each side (Rezaifar, Kabir, Taribakhsh \& Tehranian, 2008). Salmon, Eiena , Tador \& Culp (1997) determined that this combination produces walls that have full rigidity and the shear resistance required for full composite behaviour as solid walls. The use of the 3D-panel wall offers many benefits regarding the speed of construction, the saving of material, and natural disaster resistance.

\section{Design-for-Manufacture Techniques: Adoption Barriers}

Numerous publications from various countries exist that have examined the constraints and barriers of the design-for-manufacture techniques, over a significant period of time. Most of these studies have focused on identifying the barriers which influence the selection of the design-for-manufacture techniques. Table 1 provides a summary of the literature review related to the barriers of the design-for-manufacture techniques.

Table 1. Summary of the barriers of the design-for-manufacture techniques

\begin{tabular}{|c|c|c|c|c|}
\hline Study & Title & Year & Place & Barriers \\
\hline $\begin{array}{c}\text { Gibb \& } \\
\text { Isack }\end{array}$ & $\begin{array}{l}\text { Re-engineering } \\
\text { through pre- } \\
\text { assembly: client } \\
\text { expectations and } \\
\text { drivers }\end{array}$ & 2003 & UK & $\begin{array}{ll}\text { - } & \text { Lead-time } \\
\text { - } & \text { Design fixed early } \\
\text { - } & \text { Lack of suitable evaluation tools }\end{array}$ \\
\hline $\begin{array}{l}\text { Goodier } \\
\text { \& Gibb }\end{array}$ & $\begin{array}{l}\text { Barriers and } \\
\text { Opportunities for } \\
\text { Offsite in the UK }\end{array}$ & 2005 & UK & $\begin{array}{ll}\text { - } & \text { Initial cost } \\
\text { - } & \text { Lack of suitable evaluation tools } \\
\text { - } & \text { Conservatism/Negativism }\end{array}$ \\
\hline \multirow[t]{3}{*}{$\begin{array}{c}\text { Blismas } \\
\text {, et al. }\end{array}$} & $\begin{array}{l}\text { Constraints to the } \\
\text { use of off-site } \\
\text { production on } \\
\text { construction projects }\end{array}$ & 2005 & UK & $\begin{array}{ll}\text { - } & \text { Process } \\
\text { - } & \text { Lead-time } \\
\text { - } & \text { Present process \& management } \\
\text { - } & \text { Lack of suitable evaluation tools } \\
\text { - } & \text { Lack of knowledge } \\
\text { - } & \text { Lack of suppliers }\end{array}$ \\
\hline & $\begin{array}{l}\text { Benefit evaluation } \\
\text { for off-site } \\
\text { production in } \\
\text { construction }\end{array}$ & 2006 & Australia & - Lack of suitable evaluation tools \\
\hline & $\begin{array}{c}\text { Drivers, constraints } \\
\text { and future of offsite } \\
\text { manufacture in } \\
\text { Australia }\end{array}$ & 2009 & Australia & $\begin{array}{ll}\text { - } & \text { Initial cost } \\
\text { - } & \text { Codes } \\
\text { - } & \text { Lead-time } \\
\text { - } & \text { Design fixed early } \\
\text { - } & \text { Present process \& management } \\
\text { - } & \text { Conservatism/Negativism } \\
\text { - } & \text { Lack of knowledge }\end{array}$ \\
\hline
\end{tabular}

In relation to the summary information, the significant barriers of the design-formanufacture techniques can be listed as: Initial cost (cost of providing infrastructure for 
production of the elements cost); Lack of knowledge (lack of design codes, labour skills); Conservatism/negativism (resistance/unwillingness to change); Lack of suitable evaluation tools; Lack of suppliers/manufacturers; Lead-time (long lead-in time for clients, designers and contractors); and Design fixed early (difficult to change initial completed design).

\section{Method}

\section{Research Design}

The adopted methodology designed to achieve the objectives of this research was divided into two main phases.

- Phase 1: Qualitative study including a comparative analysis and a qualitative study

- Phase 2: Quantitates study involved the use of Analytic Hierarchy Process (AHP)

\section{Phase 1: Qualitative Study}

To provide a specific comparison between the design-for-manufacture techniques and the traditional approaches based on the Vietnamese construction industry's characteristics a comparative analysis was conducted. A construction project which had been completed by the use of traditional construction techniques, was redesigned and estimated the new project schedule, project cost and evaluated the safety and management effectiveness by the use of the BubbleDesk and 3D-Panel wall techniques.

To gain practical knowledge and be acquainted with professionals' points of view regarding the Vietnamese construction industry's qualities and the actual constraints that limit the popularity of the design-for-manufacture techniques in the country, a qualitative study related to the Vietnamese construction industry through interviews was conducted. Twenty experienced individuals within the Vietnamese civil engineering discipline were involved in the interviews. These discussions consisted of two city government officials from Vietnam's Department of Construction Investment and Management, individual investors, integrated designers, contractors and two senior university lecturers.

\section{Phase 2: Quantitative Study}

The quantitative study involved the use of the AHP to examine the weighting and ranking of the barriers to design for manufacture adoption. The data used in this stage of the analysis was collected using a pair-wise questionnaire survey targeting construction experts. These experts included government officials, project owners/investors, designer/consultant engineers and contractors, who have at least fine years of experience in the Vietnamese construction industry.

For the purpose of AHP analysis, a pair wise comparison questionnaire about the identified barriers was developed. The question sheets utilised in this study were distributed to key figures in the Vietnamese construction industry via email or phone call and the feedback was received through email. Furthermore, supplementary information with respect to experience, current employment position and department were required from the survey participants.

The AHP analysis essentially included two stages of evaluation specifically; the ranking list of barriers and the calculation of the agreement of ranking in certain groups of experts. Due to different viewpoints that could arise as a result of the differences in the experts' demographic information, these experts were divided in 7 groups: 5 to 10 years' experience, more than 10 years' experience, government officers, experts in private companies, project owner/investors, designers/consultant engineering, and constructors. 
The current study has the AHP model which includes two levels; level one the goal of this research; level two the five main barriers. In order to determine the relative importance of the barriers, the Super Decisions software (Saaty, 2008) was employed. The first step in using the software is creating a hierarchical super decisions model based on AHP model. The model clusters are connected by arrow from level 1 to level 2 .

Once the ranking has been calculated for each group of the experts, using the input from the pair-wise questionnaire survey. Analysis was taken to measure how good the agreement among the experts by the use of the Kendall coefficient of concordance (W). The coefficient has a range from 0 to 1 ; meaning if $(\mathrm{W})$ is equal 0 , no agreements among the experts related to the rankings; and when (W) is 1, a total agreements. The Kendall coefficient of concordance is calculated using the following formulas (Baig, 2001):

\section{Results}

\section{Qualitative Findings}

Comparative Analysis - Case Study

To provide an overview of the advantages of the design-for-manufacture techniques when applied on Vietnamese construction sites, an example project was conducted. It was a construction project that had been completed with the use of traditional construction methods, solid reinforced concrete slabs and $100 \mathrm{~mm} \& 200 \mathrm{~mm}$ brick walls. The same project would be redesigned and established by replacing reinforce concrete slabs and brick wall by BubbleDeck and 3D-panel wall techniques. The Hitosoft software was employed to estimate project cost, project schedule base on same initial labour quantities. The use of only bubble deck slabs led to $50 \%$ lighter structures, therefore, the redesign reduced the number of columns and expanding the columns' distance.

- Project Schedule: The use of BubbleDeck and 3D-panel wall techniques caused a large reduction in the amount of work required, since the number of columns was reduced by $50 \%$. It reduced the project schedule by 170 days ( $42.5 \%$ of the construction process), as only 230 days were needed to complete the construction project.

- Project Cost: The total project cost of the design-for-manufacture techniques was approximately $10 \%$ higher than the total cost of traditional methods, and this was mainly caused by the more expensive cost of materials. However, the labour costs and the equipment/construction vehicle costs decreased by $20 \%$ and more than $35 \%$, respectively.

- Management Effectiveness: The project management effectiveness significantly improved, thanks to reducing the amount of labourers present and the amount of work being done on construction sites.

- Health/Safety and Environmental Factors: The use of design-for-manufacture techniques offered safer working conditions than the use of traditional techniques, because they reduced the number of hours spent working at great heights, due to pre-fabrication at a factory. Obviously, the design-for-manufacture techniques were more environmental friendly than traditional techniques, because they made use of recycled materials and required less of other materials, such as concrete and steel.

- Project Quality: The project quality, when applying the BubbleDeck and 3D-panel wall techniques was better than it was when using traditional techniques. The BubbleDeck slabs and the 3D-panel wall were made in factories with strict standards. Additionally, even standing alone, they were considered as better quality when compared with 
traditional slabs and walls. For example, they were lighter and more resistance to sound, fire and earthquake damage.

\section{Exploratory Study}

To gather both practical knowledge and professional points of views, a qualitative study was conducted using a semi-structured interview method conducted via teleconference. Twenty experienced individuals within the Vietnamese civil engineering discipline were involved in the interviews. These included two city government officers from the Department of Construction Investment and Management, individual investors, integrated designers, constructors and two senior university lecturers. The exploratory study further showed a strong confidence that the design-for-manufacture techniques would be popular in the country through responses of specific group of key figures in the construction industry.

However, the study discovered that there are many constraints for the design of manufacture techniques to be widely used in the Vietnamese construction industry. The significant barriers and their explanation are enumerated below:

- Cost: initial cost to invest on the facilities, purchase the copyright and use the designfor-manufacture techniques; specifically material cost and services cost.

- Lack of knowledge: there is an extensive insufficiency of the technical information such as design codes and standards plus lack of guidance not to mention experience of use.

- Conservatism/Negativism: unwilling to adopt any changes in the industry or negative thinking related to the new techniques.

- Lack of suitable evaluation tools: scarcity of available tools to assess the benefit of the design for manufactures techniques in contrast with the traditional methods while continuously considering to invest on or build a new construction project.

- Lack of available suppliers: there is just a few companies which currently can provide the design-for-manufacture techniques. Moreover, the most important is that the design-for-manufacture techniques are provided as a full service, the retail material is not available.

\section{Quantitative Findings}

The AHP results show that the evaluations of experts from different disciplines are variety and depended on many factors. More specifically, the agreement among experts in group of all expert, 5-10 years' experience and more than 10 years' experience were not good. However, it indicates that the experts of the same discipline share the same viewpoints about the barriers influencing the selection of the design for manufacture in the Vietnamese construction industry. In detail, the group of government officers, group of private owners/investors, group of constructor and group of designers/consultant engineers provided good results for evaluating the barriers. Table 2 indicates the results summary of these groups. This is further illustrated in Figure 1 for better comparison. 
Table 2. Group-wise AHP results

\begin{tabular}{ccccccccc}
\hline Barriers & \multicolumn{2}{c}{ Government } & \multicolumn{2}{c}{$\begin{array}{c}\text { Private } \\
\text { Owners }\end{array}$} & \multicolumn{2}{c}{ Constructors } & Designers \\
& $\begin{array}{c}\text { Weight } \\
(\%)\end{array}$ & Ranks & $\begin{array}{c}\text { Weight } \\
(\%)\end{array}$ & Ranks & $\begin{array}{c}\text { Weight } \\
(\%)\end{array}$ & Ranks & $\begin{array}{c}\text { Weight } \\
(\%)\end{array}$ & Ranks \\
\hline Cost & 17.0 & 2 & 38.3 & 1 & 8.5 & 4 & 10.7 & 4 \\
\hline Knowledge & 8.3 & 5 & 9.5 & 5 & 15.2 & 3 & 24.6 & 2 \\
\hline Negativism & 53.0 & 1 & 10.6 & 4 & 21.1 & 2 & 3.3 & 5 \\
\hline Tools & 11.6 & 3 & 12.6 & 3 & 5.1 & 5 & 45.2 & 1 \\
\hline Suppliers & 10.1 & 4 & 29 & 2 & 50.1 & 1 & 16.2 & 3 \\
\hline
\end{tabular}

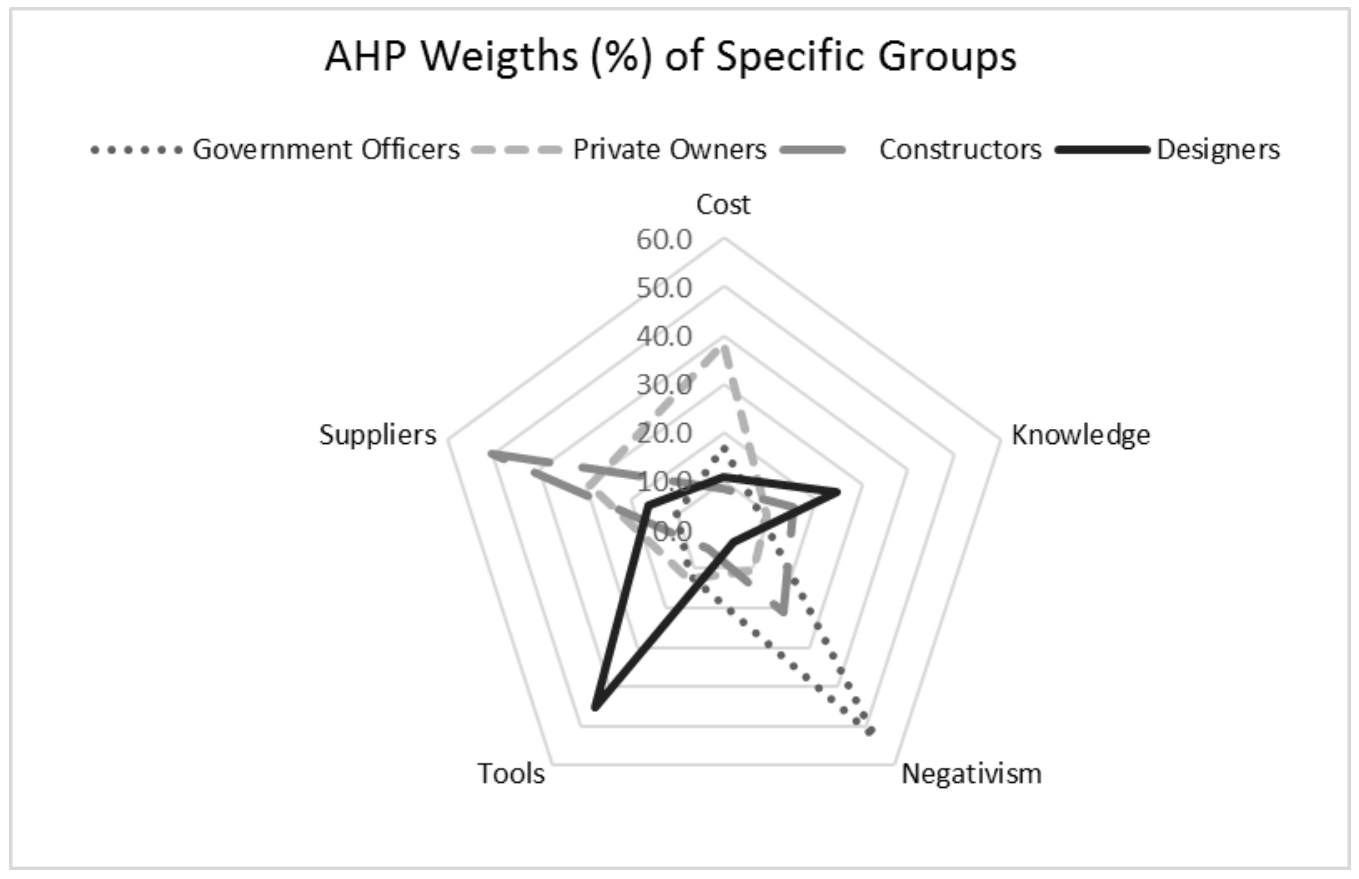

Figure 1. Overall views of the most important barrier in specific groups of experts

\section{Conclusion and Recommendations}

In general, the feasibility of the design-for-manufacture techniques have a great opportunity to become popular within the Vietnamese construction industry; however, there are still some barriers affecting their use. The case study demonstrated that the design-formanufacture techniques provided better results than traditional construction methods in regards to construction time, onsite safety, management effectiveness, and the quality of the finished project. Using these techniques also reduced the labour/equipment cost. The exploratory study indicated that many key figures within the Vietnamese construction industry believe that there's a good chance that design-for-manufacture techniques will be widely used in the future.

Nevertheless, these studies also revealed that there are many practical barriers influencing the possible selection of the design-for-manufacture techniques for use in Vietnam. These barriers include cost, a lack of knowledge, conservatism/negativism, a lack of suitable evaluation tools and a lack of available suppliers. 
The AHP analysis results show that for each specific group of experts (with each working within different disciplines), there were different critical barriers identified. Therefore, to effectively improve the uptake of the design-for-manufacture techniques in Vietnam, recommendations for specific groups of key figures within the Vietnamese construction industry are provided below:

Government: The decisions of the Vietnamese government are the most critical to improving the uptake rate of the design-for-manufacture techniques. The government can effectively remove most of the barriers blocking the use of these techniques, such as their expensive cost, and conservatism/negativism by taking these suggestions:

- Encourage more investors to participate in the material production process and to use these new techniques. This will reduce the material cost of the techniques, and moreover, increase the quantity of available suppliers.

- Research and provide design codes and standards for the design-for-manufacture techniques. This will provide the designers/consultant engineers with some muchneeded knowledge.

- Publish new policies that state that for any big construction projects invested in by the government, the use of the design-for-manufacture techniques must be considered.

- Add an educational program related to design-for-manufacture techniques to the course requirements of universities and colleges.

Designers/consultant engineers: The most significant barriers that were identified by this group are a lack of suitable evaluation tools, and a lack of knowledge. The lack of evaluation tools is a problem that can be solved more easily if a strong understanding of the design-for-manufacture techniques is gained. Therefore, the following recommendations are suggested:

- Purchase the copyright for the design-for-manufacture techniques, in order to freely use them and enable professors to provide instructions and guidelines about them to their students.

- Research and invest in a software tool that can quickly evaluate whether a specific construction project in Vietnam is suitable for the use of the new techniques or not. This type of evaluation can be conducted through software once an in-depth understanding of the techniques is gained, and a database of projects that have involved the successful use of the techniques has been created.

- Develop relationships with a wide variety of suppliers in order to select the most economical designs possible.

Constructors: A lack of available suppliers, conservatism/negativism and a lack of knowledge were identified as the most important barriers for the group of constructors. The most serious barrier (lack of available suppliers) would be solved, for the most part, by the new policies recommended for implementation by the government. However, there are still more suggestions for this group:

- Invite professors who have worked at companies and universities that have experience with design-for-manufacture techniques to introduce people to the techniques and provide guidelines. Give good employees more opportunities to gain practical knowledge via visits to construction sites that employ the techniques, and universities that teach them. 
- Organize research programs in which significant employees study the application of the design-for-manufacture techniques. Furthermore, connect with designers to provide some suggestions regarding how to improve the techniques, based on research results and practical experience.

- Be open to a wide range of suppliers. Do not only contact national suppliers, but also consider some international ones from Asian regions.

Group of Private Owners/Investors: The biggest concern of the private owners/investors was determined to be profit, which is related to the cost barrier. This barrier can be easily eliminated if the other key groups listed above follow the recommendations laid out for them. However, there is still one more recommendation for owners and investors. Instead of only considering the cost, they should consider the overall benefits that come with using the design-for-manufacture techniques, such as reduced construction time, enhanced project quality, and improved safety on the construction site.

\section{References}

Baig, M. M., 2001. Safety assessment of industrial construction projects in Saudi Arabia. Thesis (Doctoral dissertation), King Fahd University of Petroleum and Minerals.

Blismas, N., Pasquire, C., and Gibb, A. 2006. Benefit evaluation for off-site production in construction. Construction Management and Economics, 24(2), 121-130.

Blismas, N., and Wakefield, R. 2009. Drivers, constraints and the future of offsite manufacture in Australia. Construction Innovation: Information, Process, Management, 9(1), 72-83.

Blismas, N. G., Pendlebury, M., Gibb, A., and Pasquire, C. 2005. Constraints to the use of off-site production on construction projects. Architectural Engineering and Design Management, 1(3), 153-162.

BubbleDeck UK Ltd., 2008. BubbleDeck Structure Solutions - Product introduction (part 1) September 2008 [online]. Available from: http://www.bubbledeckuk.com/pdf/Product\%20Information\%20_final_20070219.pdf [Accessed 30 April 2015].

Gara, F., Ragni, L., Roia, D., and Dezi, L. 2012. Experimental behaviour and numerical analysis of floor sandwich panels. Engineering Structures, 36, 258-269.

Gibb, A., and Isack, F. 2003. Re-engineering through pre-assembly: client expectations and drivers. Building Research \& Information, 31(2), 146-160.

Goodier, C. I., and Gibb, A. G. 2005. Barriers and opportunities for offsite in the UK. IN: Abdul Samed Kazi, ed. Proceeding of the conference Systematic Innovation in the Management of Project and Processes, cib Helsinki International Joint Symposium, 148158.

Goodier, C.I. and Gibb, A.G.F. 2007. Future opportunities for offsite in the UK. Construction Management and Economics, 25, 585-595.

Goulding, J. S., Pour-rahimian, F., Arif, M., and Sharp, M. D. 2012. Offsite construction: strategic priorities for shaping the future research agenda. Journal of Architectoni. ca, 1(1), 62-73.

Hampson, K.D. and Brandon. P. 2004. Construction 2020 - A vision for Australia's Property and Construction Industry. Brisbane, Australia: CRC Construction Innovation.

Hanoi Lawyers Association. 2010. Decision No.567/QD-TTg dated April 28, 2010 of the Prime Minister [online]. Available from: http://lawfirm.vn/?a=doc\&id=2230 [Accessed: 28 April 2010].

Hai, L. V., Hung, V. D., Thi, T. M., Nguyen-Thoi, T., and Phuoc, N. T. 2013. The experimental analysis of bubbledeck slab using modified elliptical balls. In: The 
Thirteenth East Asia-Pacific Conference on Structural Engineering and Construction (EASEC-13). Proceedings of the Thirteenth East Asia-Pacific Conference on Structural Engineering and Construction (EASEC-13), G-6.

Michigan State University, 2014. Vietnam: Economy [online]. Available from http://globaledge.msu.edu/countries/vietnam/economy [Accessed 30 April 2015].

Pan, W. 2006. A decision support tool for optimising the use of offsite technologies in housebuilding. Thesis (Unpublished doctoral dissertation), Loughborough University, Loughborough.

Pan,W., Gibb, A.G.F., and Dainty, A.R.J. 2007. Perspectives of housebuilders on the use of offsite modern methods of construction. Construction Management and Economics, 25(2), 183-194.

Prabhu Teja, P., Vijay Kumar, P., Anusha, S., Mounika, C. H., and Saha, P., 2012. Structural behavior of bubble deck slab. Proceeding of the IEEE-International Conference on Advances in Engineering, Science and Management (ICAESM -2012) 30-31 March 2012, 383-388.

Saaty, T. L. 2008. Decision making with the analytic hierarchy process. International journal of services sciences, 1(1), 83-98.

Tutesigensi, A., and Phung, B.N. 2011. Vietnamese construction workers' attitude to health and safety. Proceedings of the ICE - Management, Procurement and Law, 164 (1), 41-47. 